\title{
Robotic-assisted procedures in neurosurgery
}

\author{
Jibril Osman Farah ${ }^{1}$
}

Received: 7 January 2019 / Accepted: 12 January 2019 / Published online: 26 January 2019

(C) Springer-Verlag GmbH Austria, part of Springer Nature 2019

Robotic-assisted procedures are not new in neurosurgery, particularly in functional neurosurgery and other sub-specialties.

Both the Neuromate robotic (Renishaw) arm and the Rosa robotic arm (Rosa) are routinely used in a variety of procedures: depth electrode for epilepsy, deep brain stimulation, endoscopic procedures, etc.

Generally, these are frame-based procedures (frame used for registration purpose and to guarantee sub-millimetric accuracy) and only recently frameless registration has been integrated into robotic arm software with satisfactory results [1-3].

In the present study, the authors report their experience with brain biopsies (mainly intrinsic lesions) using a frameless registration mode and the Rosa robotic arm.

The overall results are matching with those achieved with a frame-based technique (either frame or frame-based robotic arm) and are better than those achieved with a standard frameless procedure (image-guided Medtronic or Brainlab).

The overall operating time is matching standard frameless procedures with an added improvement in accuracy.

The future of stereotactic procedure is frameless registration and the utilization of robotic arm; this, in the short term, will lead to an expansion of robotic-assisted neurosurgical procedures in all neurosurgical sub-specialties (functional, oncology, skull-based, etc.) and, in long-term, will allow automatization of neurosurgical procedures in the integration of realtime imaging. Naturally, this will require a significant technological improvement but the current platforms such as Rosa and Neuromate both offer a very good starting point.

Publisher's note Springer Nature remains neutral with regard to jurisdictional claims in published maps and institutional affiliations.

\section{References}

1. Dawes W, Marcus HJ, Tisdall M, Aquilina K (2018) Robot-assisted stereotactic brainstem biopsy in children: prospective cohort study. J Robot Surg. https://doi.org/10.1007/s11701-018-0899-x

2. De Benedictis A, Trezza A, Carai A, Genovese E, Procaccini E, Messina R, Randi F, Cossu S, Esposito G, Palma P, Amante P, Rizzi M, Marras CE (2017) Robot-assisted procedures in pediatric neurosurgery. Neurosurg Focus. https://doi.org/10.3171/2017.2. FOCUS16579

3. Yasin H, Hoff HJ, Blümcke I, Simon M (2018) Experience with 102 frameless stereotactic biopsies using the neuromate robotic device. World Neurosurg. https://doi.org/10.1016/j.wneu.2018.11.187
This article is part of the Topical Collection on Brain Tumors

Jibril Osman Farah

jibril@ doctors.org.uk

1 The Walton Centre for Neurology and Neurosurgery, Liverpool, UK 